\title{
A CONCRETIZAÇÃO DA CONVENÇÃO SOBRE OS DIREITOS DAS PESSOAS COM DEFICIÊNCIA A PARTIR DA TEORIA DE JOAQUÍN HERRERA FLORES
}

\author{
Jéssica Ribeiro Barreto* \\ Raimundo Wilson Gama Raiol** \\ Denisson Gonçalves Chaves***
}

\section{Resumo:}

Busca-se refletir em que medida a teoria crítica de Direitos Humanos de Joaquín Herrera Flores pode contribuir para a concretização da Convenção sobre os Direitos das Pessoas com Deficiência mediante o acompanhamento permanente do processo de implementação de tal tratado. Desse modo, será utilizado na presente pesquisa exploratória, o método hipotéticodedutivo, bem como a utilização de técnicas de pesquisa bibliográfica. É possível inferir a contribuição da teoria crítica de Herrera Flores para a concretização da CDPD ao fomentar processos de luta e construção de práticas empoderadas assegurar as garantias desse grupo.

Palavras-chave: Concretização. Pessoas com Deficiência. Teoria Crítica. Direitos Humanos. Joaquín Herrera Flores.

\section{THE ACCOMPLISHMENT OF THE CONVENTION ON THE RIGHTS OF PERSONS WITH DISABILITIES FROM THE CRITICAL THEORY OF JOAQUÍN HERRERA FLORES}

\begin{abstract}
:
Search to reflect to what extent the critical Human Rights theory of Joaquín Herrera Flores can contribute to the realization of the Convention on the Rights of Persons with Disabilities through the permanent monitoring of the process of implementing of this treaty. Thus, it will be used in this exploratory research, the hypothetical-deductive method, as well as the use of bibliographic research technic. It's possible to infer the contribution of Herrera Flores' critical theory to the accomplishment of the CRPD by fomenting processes of struggle and the construction of empowered practices to ensure the guarantees of this group.

\footnotetext{
* Mestranda pelo Programa de Pós-Graduação em Direito do Instituto de Ciências Jurídicas, da Universidade Federal do Pará. Bacharel em Direito pela Universidade da Amazônia. Membra da Clínica de Direitos Humanos CADHU.

** Doutor em Direitos Fundamentais e Relações Sociais, pelo Programa de Pós-Graduação em Direito, do Instituto de Ciências Jurídicas, da Universidade Federal do Pará. Professor Associado, exercendo a docência no Curso de Graduação em Direito e no referido Programa. Membro da Academia Paraense de Letras Jurídicas. Advogado.

*** Doutorando em Direito pela Universidade Federal do Pará (UFPA). Mestre em Direito e Instituições do Sistema de Justiça (UFMA); Bacharel em Direito pela Universidade Federal do Maranhão (UFMA); Professor efetivo na Universidade Federal do Maranhão (UFMA); Professor na Unidade de Ensino Superior do Sul do Maranhão (UNISULMA); Pesquisador no Grupo de Pesquisa Cultura, Direito e Sociedade (UFMA); Pesquisador no Grupo de Estudos e Pesquisa Filosofia Social e Teoria Crítica (UFMA); Pesquisador do Núcleo de Estudos e Pesquisas em Estado, Políticas Públicas Educacionais e Democracia (UEMASUL); Pesquisador no Grupo de Pesquisa Teorias Normativas do Direito (UFPA). Coordenador do Núcleo de Pesquisas Jurídicas de Imperatriz Democracia e Direitos Fundamentais (NUPEJI).
} 
Keywords: Accomplishment. People with disabilities. Critical Theory. Human Rights. Joaquín Herrera Flores.

\section{1 - INTRODUÇÃO}

A Convenção sobre os Direitos das Pessoas com Deficiência (CDPD), aprovada pela Organização das Nações Unidas (ONU), em 2007, representou um marco para a proteção dos direitos desse grupo, principalmente porque é um tratado complexo que abarca vários tipos de garantias ao seu público-alvo, bem como estabeleceu a obrigação dos Estados em constituir com uma base de dados referente às políticas públicas desenvolvidas e, principalmente, pelo fato de prever um sistema de acompanhamento de sua implementação. (LOPES, 2007). Desse modo, vale questionar em que medida a teoria crítica de Direitos Humanos de Joaquín Herrera Flores pode contribuir para a concretização da CDPD através do acompanhamento permanente do processo de implementação de tal tratado.

A afirmação dos direitos humanos a partir do pós-guerra buscou reconhecer valores universais que protegessem a dignidade do ser humano delineando o sistema global de proteção dos direitos humanos. Foram elaborados a Declaração Universal dos Direitos Humanos (DUDH) de 1948 da ONU e outros instrumentos internacionais como os Pactos Internacionais dos Direitos Civis e Políticos (PIDCP) e dos Direitos Sociais, Econômicos e Culturais (PIDESC) de 1966. Em seguida, houve a celebração de outras convenções que buscavam tutelar sujeitos vulneráveis como mulheres, negros, crianças e pessoas com deficiência, levando a ONU a criar o sistema especial de proteção. Não obstante, os estudos dos direitos humanos ganharam recentemente um foco de atenção sob uma perspectiva crítica que busca refletir uma nova função desse grupo de direitos para o ser humano, bem como sua aplicação prática para além do texto normativo.

Desse modo, busca-se abordar a teoria crítica de direitos humanos criada pelo professor espanhol Joaquín Herrera Flores (2005), o qual propõe uma nova leitura acerca de tal categoria de direitos, no sentido de repensar suas características culturais e destacar o seu cunho procedimental para afirmar processos de lutas de garantias nas práticas sociais para analisar a gênese e a concretização da Convenção sobre os Direitos das Pessoas com Deficiência.

A história dos direitos das pessoas com deficiência passou por diversas etapas, desde uma postura de intolerância, de invisibilidade e de assistencial até a atual fase, a de inclusão 
social, com a positivação de direitos humanos (Piovesan, 2017). Não obstante a positivação de inúmeras prerrogativas para as pessoas com deficiência em vários níveis - a exemplo do Brasil que possui o Estatuto da Pessoa com Deficiência (Lei $n^{\circ}$ 13.146/2015) e uma miríade de leis sobre o tema - a garantia efetiva de direitos desse grupo da população ainda se mostra um desafio a ser alcançado, tanto no âmbito interno quanto no externo, mesmo passados mais de 10 anos da celebração da CDPD. Nesse sentido, é necessário refletir acerca de uma quinta fase, a do acompanhamento da concretização dos direitos desse grupo, o qual deve ser realizado de modo permanente.

Assim, para responder ao problema apresentado será utilizado o método hipotéticodedutivo, pelo qual se busca elaborar uma hipótese acerca de uma possível contribuição da Teoria Crítica de Direitos Humanos, de Joaquín Herrera Flores, para a concretização dos direitos previstos na CDPD. Serão utilizadas a pesquisa exploratória, que inicia o estudo sobre o tema, e a bibliográfica, realizada por meio de busca de artigos científicos sobre o assunto em plataformas online de bancos de dados de artigos científicos, com as seguintes palavras-chave: teoria crítica; direito internacional; pessoas com deficiência; principalmente o trabalho de Aloisio Krohling e Yumi Miyamoto (2011) sob o título de "A contribuição da teoria crítica do direito internacional dos direitos humanos aos direitos das pessoas com deficiência”, além de outros livros sobre o tema, bem como a análise das obras de Herrera Flores denominadas "A reinvenção dos direitos humanos" (2009) e "Los derechos humanos como productos culturales: CRÍTICA DEL HUMANISMO ABSTRACTO” (2005).

Desse modo, a primeira parte do presente trabalho tratará sobre o sistema global de direitos humanos, apresentando suas origens, estrutura e fundamento e analisará a Convenção sobre os Direitos das Pessoas com Deficiência. A segunda parte abordará a teoria crítica de direitos humanos de Joaquín Herrera Flores. A terceira elaborará a relação entre a teoria crítica de Herrera Flores para o estabelecimento de uma quinta fase, ou seja, de permanente acompanhamento da concretização de mencionado tratado.

\section{2 - O SISTEMA GLOBAL DE DIREITOS HUMANOS E A CONVENÇÃO SOBRE OS DIREITOS DAS PESSOAS COM DEFICIÊNCIA}

Antes de aprofundar a análise sobre a CDPD, é necessário situar em qual sistema está situada e o seu contexto de surgimento. O Pós $2^{\text {a }}$ Guerra Mundial acarretou profundas 
mudanças na sociedade internacional, quais sejam, de cunho jurídico, político, social e cultural. Além disso, provocou uma reflexão profunda acerca dos valores da sociedade e a busca por uma proteção ganhou força com base em um paradigma: a dignidade do ser humano. Tal contexto iniciou a fase de internacionalização dos direitos humanos, por meio do que se reconhece um esforço na tentativa de reconstrução dos direitos inerentes às pessoas do nível individual ao global, disso decorrendo que a

\begin{abstract}
"necessidade de uma ação internacional mais eficaz para a proteção dos direitos humanos impulsionou o processo de internacionalização desses direitos, culminando na criação da sistemática normativa de proteção internacional, que faz possível a responsabilização do Estado no domínio internacional quando as instituições nacionais se mostram falhas ou omissas na tarefa de proteger os direitos humanos. (PIOVESAN, 2018)."
\end{abstract}

Devido à essa proteção internacional, esses direitos ganharam características como superioridade normativa devido ao ius cogens das normas internacionais, universalidade, interdependência, indivisibilidade, indisponibilidade, historicidade entre outras características. Não obstante, vale destacar o caráter universal desses direitos, pois tal concepção é bastante controversa, como será mostrado no decorrer do texto, porque, segundo Paulo Portela (2018, p. 908 e 909), “os direitos humanos referem-se a todos os membros da espécie humana, sem distinção de qualquer espécie, seja de sexo, raça, cor, origem étnica, nacional ou social, nacionalidade, idade, religião, orientação sexual ou qualquer outra condição."

Sob essa ótica, instituições como a Organização das Nações Unidas foram criadas e documentos pactuados para reconhecer as garantias que mereciam ser protegidas em escala global, a exemplo da Declaração Universal dos Direitos Humanos (DUDH) de 1948, da ONU, e outros instrumentos internacionais, como os Pactos Internacionais dos Direitos Civis e Políticos (PIDCP) e dos Direitos Sociais, Econômicos e Culturais (PIDESC) de $1966 .{ }^{2}$ O propósito da proteção geral no nível externo era conferir o máximo de garantias a todo e qualquer indivíduo, independentemente de sua condição.

Contudo, a tentativa de generalização causou debates na comunidade internacional principalmente entre os filiados à concepção relativista acerca dos direitos humanos, para os quais "a noção de direito está estritamente relacionada ao sistema político, econômico, cultural,

\footnotetext{
${ }^{2}$ Tal vertente pode ser encontrada em expressões com cunho de generalidade: "Todos os seres humanos nascem livres e iguais em dignidade e direitos" (Artigo I, DUDH); "garantir a todos os indivíduos que se achem em seu território e que estejam sujeitos a sua jurisdição os direitos reconhecidos no presente Pacto, sem discriminação alguma por motivo de raça, cor, sexo, língua, religião, opinião política ou de outra natureza, origem nacional ou social, situação econômica, nascimento ou qualquer condição" (Artigo II, PIDCP) e "assegurar a homens e mulheres igualdade no gozo de todos os direitos econômicos, sociais e culturais enumerados no presente Pacto." (Artigo II, PIDESC).
} 
social e moral vigente em determinada sociedade" (PIOVESAN, 2018, p. 211). Ademais, tal discussão afeta principalmente o modo de aplicação e interpretação de tais direitos pelos Estados signatários dos tratados, conforme o entendimento de André Ramos:

\begin{abstract}
"o Direito Internacional dos Direitos Humanos convive com um grande desafio, muitas vezes olvidado: criar, por meio de tratados e costumes internacionais, um rol amplo de direitos e um grupo de órgãos judiciais ou quase judiciais que, por sua vez, determinarão interpretações comuns dos mais importantes temas das heterogêneas sociedades humanas (RAMOS, 2016, p. 91).
\end{abstract}

Outras críticas ao sistema universalista da ONU dizem respeito também à diversidade referente aos indivíduos, pois a descrição genérica dos tratados muitas vezes não leva em conta especificidades de grupos vulneráveis, que são "grupos de pessoas que mais facilmente tem seus direitos humanos violados" (GUIMARÃES, 1996, p. 371) por possuírem vulnerabilidade em razão da idade (idosos e crianças), gênero, raça, deficiência entre outros.

A demanda por uma proteção especial pelo sistema onusiano em relação aos grupos vulneráveis decorreu de um processo que Noberto Bobbio (2004) denominou de especificação dos sujeitos titulares de direitos considerando-os em sua concretude. Desse modo, surgiram vários tratados ${ }^{3}$ que formaram o sistema especial de proteção da $\mathrm{ONU}$, cujas convenções são destinadas a determinados grupos de indivíduos que sofrem violações de direitos específicas (PIOVESAN, 2018).

A CDPD surgiu, nesse contexto, como ponto culminante de um esforço internacional em prol de um movimento de afirmação das garantias desse grupo, desde os anos 70, em que as pessoas com deficiência começaram a ser reconhecidas como "sujeitos pelo critério do direito e não pelo critério da atenção" (LOPES, 2007, p. 45).

A partir desse momento, vários documentos pontuais foram elaborados por vários organismos internacionais para proteger esse público, como a Recomendação $\mathrm{n}^{\circ} 99$ da Organização Internacional do Trabalho (OIT) sobre a reabilitação de pessoas portadoras de deficiência ${ }^{4}$, a Resolução 37/52 da ONU que estabelece o Plano de Ação Mundial relativo às Pessoas com Deficiência e, por fim, a Convenção Interamericana para a Eliminação de Todas as Formas de Discriminação contra as Pessoas Portadoras de Deficiência, de 1999, da Organização dos Estados Americanos (OEA) (LOPES, 2007).

\footnotetext{
${ }^{3}$ Convenção sobre os Direitos da Criança (1959), Convenção Internacional sobre a Eliminação de todas as formas de Discriminação Racial, Convenção sobre a Eliminação de todas as formas de Discriminação contra a Mulher (1967), entre outras.

${ }^{4}$ Nota-se que a terminologia utilizada por várias normas internacionais e nacionais anteriores à CDPD - inclusive a Constituição Federal de 1988 (CF/88) - é de portador de deficiência, mas cujo paradigma foi mudado pelo referido tratado para o reconhecimento da denominação de pessoa com deficiência.
} 
A Resolução nº 56/186 de 2001 da Assembleia Geral da ONU aprovou a criação de um Comitê ad hoc para examinar propostas referentes à elaboração de um tratado integral para promoção e proteção dos direitos e da dignidade das pessoas com deficiência. Em agosto de 2002, ocorreu a $1^{\text {a }}$ reunião do comitê - que ocorreria até 2006 -, a qual estabeleceu o lema da referida convenção intitulado de "Nothing about us, without us", evidenciando o sentimento do movimento em prol da afirmação dos direitos das pessoas com deficiência, o que envolveu Estados Partes e organizações representativas de pessoas com deficiência que participaram das reuniões do Comitê (LOPES, 2007). Ademais, vale destacar, segundo Laís Lopes, (2007, p. 51) que "a sociedade civil teve uma participação significativa durante todo o processo, tendo articulado em todos os momentos de maneira organizada por meio do IDC" 6

A Convenção sobre os Direitos das Pessoas com Deficiência foi celebrada na cidade de Nova York, em 2007, e procurou estabelecer o modelo social dos direitos humanos de seu público alvo (LOPES, 2007), cujo propósito está exposto em seu artigo 1, isto é, promover, proteger e assegurar o exercício pleno e equitativo de todos os direitos humanos e liberdades fundamentais por todas as pessoas com deficiência e promover o respeito pela sua dignidade inerente.

A Convenção de Nova York é um tratado complexo que estabelece princípios norteadores (como o da acessibilidade e não discriminação entre outros), obrigações estatais no que tange à adoção de medidas legislativas e administrativas, políticas públicas para assegurar e garantir os direitos das pessoas com deficiência e, principalmente, direitos civis, políticos, sociais, culturais e econômicos e também a grupos duplamente vulneráveis como mulheres e crianças com deficiência. Ademais, vale ressaltar que a CDPD prevê um sistema de monitoramento (Artigos 33 a 40) acerca de sua implementação pelos Estados Signatários, o que envolve um sistema não-judicial com o envio de relatórios periódicos pelos Estados Partes, um Comitê específico da convenção que analisa tais documentos e elabora recomendações e recebe petições individuais, conforme o Protocolo Facultativo do referido tratado.

No Brasil, a CDPD foi ratificada pelo Decreto $\mathrm{n}^{\circ} 6.949$ de 25 de agosto de 2009, conforme o rito do art. $5^{\circ}, \S 3^{\circ}$ da $\mathrm{CF} / 88$, o que lhe confere status de Emenda Constitucional de maneira material e formal, considerando uma interpretação sistemática e teleológica dos $\S \S 1^{\circ} \mathrm{e}$ $2^{\circ}$ do referido dispositivo constitucional, segundo Flávia Piovesan (2018).

\footnotetext{
${ }^{5}$ Nada sobre nós sem nós.

${ }^{6}$ International Disability Caucus, uma rede internacional da sociedade civil que participou durante as negociações da CDPD.
} 
Após a incorporação do referido tratado pelo país, foram realizadas medidas como a promulgação da Lei n ${ }^{o}$ 13.146/2015 (Estatuto da Pessoa com Deficiência ou também chamada de Lei Brasileira de Inclusão), que consiste na legislação interna sobre o assunto e que está em consonância à CDPD sobre os direitos desses indivíduos, divide competências entre os entes federativos, define crimes entre outras ações, bem como a previsão de políticas públicas, como o Plano Viver sem Limite de 2011, que acena com a primeira política pública articulada para promover os direitos das pessoas com deficiência e outras ações governamentais.

\section{3 -A TEORIA CRÍTICA DE JOAQUÍN HERRERA FLORES}

Joaquín Herrera Flores era um professor espanhol que obteve seu doutorado em Direito pela Universidad de Sevilla, lecionou as disciplinas de Filosofia do Direito e Teoria da Cultura na Universidad Pablo de Olavide de Sevilla, bem como foi diretor do Programa de Doutorado em Direitos Humanos e Desenvolvimento da referida universidade espanhola ${ }^{7}$.

O jusfilósofo espanhol propõe "nova perspectiva dos direitos como processos institucionais e sociais que possibilitem a abertura e a consolidação de espaços de luta pela dignidade humana (HERRERA FLORES, 2009, p 19). Tal teoria está principalmente explanada em duas de suas obras intituladas de Los derechos humanos como productos culturales (2005) e A (re)invenção dos direitos humanos (2009).

No capítulo introdutório da primeira obra citada, criticou a ordem hegemônica dos conceitos universalistas proposto pelos sistemas internacionais de direitos humanos, pois entendia que a cultura universalista que dominou a cultura ocidental possuía uma forte carga valorativa das práticas europeias (HERRERA FLORES, 2005). Ademais, o autor já se questionava acerca da concepção dos direitos humanos, propondo uma teoria que os conceituava como um produto surgido em contextos de relações concretas e complexas que se espalharam ao redor do mundo:

Los derechos humanos, como productos culturales, constituyen, pues, un conjunto de
pautas, reglas, propuestas de acción y modos o formas de articulación de acciones
humanas cuyos límites y fronteras son muy difíciles de determinar de un modo
completo o definitivo (HERRERA FLORES, 2005, p. 30).

Assim, vale destacar que o autor defende que todas as formações sociais possuem maneiras culturais próprias de explicação, interpretação e intervenção no mundo e concentração

\footnotetext{
${ }^{7}$ Informações retiradas da biografia do autor. Disponível em: 〈http://www.joaquinherreraflores.org.br/biografia/> Acesso em 24, mai de 2020.
} 
de ações rumo ao alcance à dignidade que consistiria no poder de agir para encontrar seu lugar no mundo, a qual seria um conceito universal para todos os grupos em seus processos de luta envolvendo aspectos jurídicos, políticos, econômicos e sócias, pela garantia de bens necessários para se viver dignamente (HERRERA FLORES, 2005). "Esta dialogicidade acaba provocando o enriquecimento da discussão com as diferenças, destacando interculturalidade de forma a envolver as desigualdades intergrupais” (KROHLING; MIYAMOTO, 2011, p. 196).

A teoria crítica de Joaquín Herrera Flores, esboçada no primeiro capítulo da obra Los derechos humanos como productos culturales: CRÍTICA DEL HUMANISMO ABSTRACTO (2005), retoma à premissa da concepção de entendimento dos direitos humanos como processos de lutas em relação ao modelo econômico capitalista que, com sua lógica de dominação de mercado, exclui e priva uma parcela da população de seus direitos. Nessa direção, o autor sugere instrumentos para desenvolver capacidades de lutas através do acesso de forma generalizada e igualitária aos bens para alcançar uma vida digna (HERRERA FLORES, 2005).

Tais mecanismos são propostos por HERRERA FLORES (2005) por intermédio do que denominou de decisões iniciais:

\begin{tabular}{|c|c|}
\hline Pensar é pensar de outro modo & $\begin{array}{l}\text { Elaborar novas formas de evidenciar as diferenças } \\
\text { culturais e promover espaços de encontro e } \\
\text { empoderamento dos grupos no processo social. }\end{array}$ \\
\hline $\begin{array}{l}\text { Da negatividade dialética a } \\
\text { afirmação ontológica e axiológica }\end{array}$ & $\begin{array}{l}\text { Valorização de novas maneiras de pensar os } \\
\text { processos de luta a partir de construções positivas } \\
\text { acerca dos objetos de luta e seus valores, mas não } \\
\text { significando o abandono do pensamento tradicional, } \\
\text { apenas uma reflexão crítica. }\end{array}$ \\
\hline $\begin{array}{c}\text { Pensar as lutas pela dignidade } \\
\text { humana significa problematizar a } \\
\text { realidade }\end{array}$ & $\begin{array}{l}\text { Problematizar a realidade em relação à construção } \\
\text { de espaços de encontros positivos que podem } \\
\text { intervir no mundo, a partir de posições críticas e } \\
\text { diferenciadas. }\end{array}$ \\
\hline Da utopia as heterotopias & $\begin{array}{l}\text { A utopia a que Herrera Flores (2005) se refere é a } \\
\text { construção de novos lugares por meio de uma } \\
\text { mudança radical das condições existenciais, } \\
\text { enquanto que na heteropia tais mudanças ocorrem } \\
\text { originando um novo futuro. }\end{array}$ \\
\hline $\begin{array}{l}\text { A indignação frente ao intolerável } \\
\text { nos deve induzir ao encontro positivo } \\
\text { e afirmativo de vontades críticas }\end{array}$ & $\begin{array}{l}\text { Para exercer uma vontade crítica, é necessário ser } \\
\text { capaz de se indignar com o contexto social ao seu } \\
\text { redor. }\end{array}$ \\
\hline Nem tudo vale igual & $\begin{array}{l}\text { O autor destaca conceitos como realismo relativista } \\
\text { e relacional que consiste em reconhecer que há uma } \\
\text { multiplicidade de interpretações e intervenções de } \\
\text { acordo com as relações que existem no meio. }\end{array}$ \\
\hline
\end{tabular}

Tabela 1: elaborada pelos autores. 
Outro conceito importante na teoria crítica de Herrera Flores (2005) diz respeito ao empoderamento dos agentes dos processos de luta pelos direitos humanos que foram subestimados no processo de construção social pela dominação hegemônica. Tal processo ocorrerá por meio de atitudes como denomina o autor de "hacemos por nosotros mismos" (HERRERA FLORES, 2009, p. 59) que deem a esses sujeitos alternativas de um diálogo transcultural em uma igualdade substancial.

Em sua obra “A (re)invenção dos direitos humanos”, Joaquín Herrera Flores (2009, p. 17 e 18) define que "o direito, nacional ou internacional não é mais que uma técnica procedimental que estabelece formas para ter acesso aos bens por parte da sociedade" . Além disso, o autor propõe uma "okupação" dos espaços em suas variadas acepções políticas, sociais, econômicas, individuais e culturais que foram negados a certos sujeitos pelo processo de globalização e sua dominação hegemônica.

O referido processo de "okupação" pelos agentes das lutas sociais ocorre, segundo o autor, por imperio da intervenção da realidade como consequência de: pautas políticas de transformação e empoderamento; detecção e intervenção direta nas causas principais dos processos culturais; adoção da ótica do fazer humano em detrimento de práticas mercadológicas; construir uma história mediante lutas por dignidade, desenvolvendo um imaginário social instituidor de novas ações pela afirmação da vida digna; desenvolvimento de uma nova estética da política no sentido de uma recuperação da força do normativo por via de processos criativos de construção do espaço político; desconstruir o processo de "coisificação" do mundo para compreender a realidade social como um ponto de jornada e chegada das lutas culturais; desenvolvimento de uma consciência de que os seres humanos fazem parte do ambiente e não estão em um local à parte; proposição de pautas para uma contramodernização inflexiva, como consequência de denúncias relativas à práticas comerciais com a seguinte substituição por leis culturais que afetam as instituições, as dinâmicas das relações e a política; realizar uma harmonização entre a teoria e a realidade, assumindo compromissos de luta contra padrões excludentes e dominantes, a exemplo do patriarcalismo; e, por fim, libertar a vida e o desejo de construir novos espaços de relações. 


\section{4 - A QUINTA FASE DA AFIRMAÇÃO DOS DIREITOS DAS PESSOAS COM DEFICIÊNCIA: A CONCRETIZAÇÃO DA CDPD A PARTIR DA TEORIA DE JOAQUÍN HERRERA FLORES}

O propósito de analisar criticamente a concretização da Convenção sobre os Direitos das Pessoas com Deficiência da ONU é repensar práticas contínuas de efetivação dos direitos desse grupo vulnerável na realidade social. Embora aparentemente a crítica da teoria de Herrera Flores não parta dos mesmos pressupostos de construção dos direitos no âmbito do sistema onusiano, é possível encontrar pontos de toque e contribuições. Tal relação foi primeiramente trabalhada por Aloisio Krohling e Yumi Miyamoto, cujo ponto de partida para a crítica à concepção tradicional dos direitos humanos e principalmente os direitos das pessoas com deficiência é a de que

criticar não significa destruir para criar ou negar para afirmar, pois o pensamento crítico tem a característica precípua de ser sempre criativo e afirmativo, apresentando alternativas à ordem existente, rompendo com o estigma que impede a maioria dos seres humanos de exercer suas capacidades genéricas de fazer e, principalmente, de apresentar alternativas (KROHLING; MIYAMOTO, 2011, p. 199).

Diante disso, é preciso reconhecer que houve avanços no caminho da afirmação dos direitos das pessoas com deficiência no plano internacional e nacional, conforme o entendimento de Flávia Piovesan:

A história da construção dos direitos humanos das pessoas com deficiência
compreende quatro fases: a) uma fase de intolerância em relação
às pessoas com deficiência, em que a deficiência simbolizava impureza,
pecado, ou mesmo, castigo divino; b) uma fase marcada pela invisibilidade das
pessoas com deficiência; c) uma terceira fase orientada por uma
ótica assistencialista, pautada na perspectiva médica e biológica de que a
deficiência era uma "doença a ser curada", sendo o foco centrado no indivíduo
"portador da enfermidade"; e d) finalmente uma quarta fase orientada pelo
paradigma dos direitos humanos, em que emergem os direitos
à inclusão social, com ênfase na relação da pessoa com deficiência e do
meio em que ela se insere, bem como na necessidade de eliminar obstáculos e
barreiras superáveis, sejam elas culturais, físicas ou sociais,
que impeçam o pleno exercício de direitos humanos (PIOVESAN, 2017, p. 125).
(grifo nosso)

Tal processo de aquisição de direitos foi importante, para conferir proteção a esse grupo populacional e se deu em grande pela pressão da sociedade civil e das pessoas com deficiência. A CDPD "foi essencialmente uma consequência do desenvolvimento de uma série de reflexões no âmbito do movimento internacional de direitos humanos: 
consolidou avanços, estimulou caminhos, sintetizou visões e antecipou enormes desafios" (GALINDO, 2014, p. 89)

O Estado brasileiro adotou medidas para assegurar os direitos das pessoas com deficiência, das quais vale destacar as políticas públicas, a exemplo do Programa Nacional de Direitos Humanos III de 2010, cujo eixo orientador: III - Universalizar Direitos em um Contexto de Desigualdades possui diretrizes para a promoção dos direitos desse grupo populacional, bem como o Plano Nacional dos Direitos da Pessoa com Deficiência - Viver Sem Limite no ano de 2011, o qual possui o propósito de promover por meio da integração e articulação de políticas, programas e ações, bem como o exercício pleno e equitativo dos direitos das pessoas com deficiência, conforme dispõe o art. $1^{\circ}$ do Decreto . Ademais, a promulgação da Lei $n^{\circ}$ 13.146/2015, chamada de Estatuto da Pessoa com Deficiência, também cumpre uma das disposições da CDPD, além de ser uma importante norma interna sobre a matéria. Vale destacar que atualmente o governo tem promovido políticas específicas ou inseridas em políticas maiores de direitos humanos, mas há ausências de dados acerca de sua implementação que ocorrem pela retirada da disponibilização dos relatórios periódicos nacionais do portal eletrônico do Ministério da Mulher, Família e Direitos Humanos responsável pela Secretaria dos Direitos das Pessoas com Deficiência, falta de atualização dos números acerca das políticas públicas que atendam ao referido público-alvo e a presença de poucas pesquisas científicas promovidas por Instituições de Ensino Superior e organizações da sociedade civil que realizem uma análise empírica e quantitativa acerca dessas políticas.

Não obstante, como essas políticas tem sido acompanhadas, ou melhor, monitoradas? Vale destacar, a previsão do sistema de monitoramento da referida Convenção, estabelecido entre os artigos 33 a 40 que define a obrigação dos Estados em elaborarem relatórios periódicos acerca das medidas de implementação da CDPD em seus territórios. Como resultado inicial, foram produzidos no país um relatório inicial em 2008 contendo a explanação das medidas que o Estado realizou para o cumprimento da referida convenção e outro, complementar, em 2015, para responder às observações conclusivas do Comitê do mencionado diploma internacional.

O que vem depois da norma? Ou melhor, o que vem depois da quarta e última fase de afirmação do modelo social de direitos humanos das pessoas com deficiência? Apenas a previsão de direitos em documentos normativos não transforma palavras em garantias efetivas na realidade social. Joaquín Herrera Flores realiza um questionamento semelhante, como se pode verificar: 
Después de más de cincuenta años de vigencia e una Declaración de Derechos Humanos que se autoproclama como universal, los derechos humanos siguen sin cumplirse en gran parte de nuestro mundo. Y esto ¿por qué ocurre? ¿Sólo por la falta de voluntad de los gobiernos representados en la Asamblea General de la ONU? ¿O no será mejor decir que el contexto de relaciones sociales dominado por la forma económica dominante en el sistema mundial ha impedido su real y concreta puesta en práctica? La historia de los incumplimientos de los derechos es tan larga, tan continuada y, desafortunadamente, tan actual que no es preciso siquiera ahondar más en ella. Consultemos únicamente los informes anuales promovidos por Naciones Unidas y constataremos el abismo cada vez mayor que existe entre lo proclamado en la declaración y las realidades concretas en que viven las cuatro quintas partes de la humanidad (HERRERA FLORES, 2005, p. 19).

Nesse sentido, é relevante realizar tal reflexão em relação ao nível de concretização da CDPD e da Lei Brasileira de Inclusão no país, os quais necessitam ser refletidos de forma permanente, principalmente no que diz respeito aos dados acerca da efetivação dos direitos dispostos pelas referidas normas que são comumente desatualizados, no que tange ao fornecimento dos bens que são o objeto de tutela jurídica, das quais as pessoas com deficiência precisam de que sejam garantidos em sua realidade. Na mesma senda, entendem Aloisio Krohling e Yumi Miyamoto:

uma questão relevante é ressaltar que os direitos humanos não podem ser confundidos
com os direitos positivados no âmbito nacional ou internacional, uma vez que
nenhuma constituição e, muito menos, um tratado internacional "criam" direitos
humanos, pois a nossa maior reflexão consiste em descobrir como um "direito
humano" consegue se transformar em direito para a obtenção de garantia jurídica com
o fim precípuo de sua implantação e efetividade (KROHLING; MIYAMOTO, 2011,
p. 199).

O processo de garantia dos direitos humanos está terminado com a elaboração de normas protetivas dos direitos das pessoas com deficiência? Essas respostas precisam de contínuos processos de luta pela afirmação permanente dos direitos das pessoas com deficiência. A quarta fase citada por Piovesan (2017) foi e ainda é importante para os direitos humanos desse grupo vulnerável, uma vez que provocou uma transformação paradigmática na relação entre o indivíduo com deficiência e o seu respectivo meio, pois que não é visto como alguém a ser ajudado, mas um sujeito com titularidades de direitos. Somado a isso, pode-se relacionar a perspectiva de Herrera Flores (2005) ao propor o empoderamento dos sujeitos, no caso em análise, as pessoas com deficiência.

o empoderamento das pessoas com deficiência passa a ser o ponto central através do uso do poder pessoal para fazer escolhas, tomar decisões e assumir o controle da situação de cada um e sua responsabilidade na contribuição com seus talentos para mudar a sociedade rumo à inclusão de todas as pessoas, com ou sem deficiência, com o crescimento da consciência de que a inclusão dessas pessoas é uma questão de ética, cidadania e redução da desigualdade social, cujo processo, no entanto, exige um 
esforço na superação de barreiras e preconceitos (KROHLING; MIYAMOTO, 2011, p. 205).

Nesse sentido, é necessário fomentar uma quinta fase do processo de efetivação dos direitos humanos das pessoas com deficiência denominada de monitoramento, tomando-se como base duas frentes de luta por meio do empoderamento mútuo desses sujeitos, seja em nível individual seja grupal, para que esses sejam capazes de manter um constante processo de reivindicação ao acesso aos bens necessários a uma vida digna e o monitoramento das políticas públicas que venham a atender a esse público. Considerando a teoria de Herrera Flores (2005), deve-se fomentar espaços de diálogo em associações de pessoas com deficiência para difundir discussões acerca de práticas sociais, no entorno desses sujeitos, tendo como pressuposto a máxima do professor espanhol de "fazer por nós mesmos", com pesquisas acerca de demandas sociais desse grupo e formação de base de dados que subsidiem as decisões acerca da concretização dos direitos das pessoas com deficiência.

\section{5 - CONCLUSÃO}

Por conseguinte, a presente pesquisa buscou refletir acerca de novas formas de se pensar a concretização da Convenção sobre os Direitos das Pessoas com Deficiência da ONU e, por consequência, os direitos humanos desse grupo de indivíduos. Tal reflexão se utilizou do referencial da teoria crítica dos direitos humanos do jusfilósofo espanhol Joaquín Herrera Flores.

Primeiro, analisou-se o processo histórico da internacionalização dos direitos humanos no pós-guerra para verificar as influências do estabelecimento de um regime universal de direitos humanos que forneceu, a priori, garantias para os indivíduos. Contudo, reflexões acerca do fato que de o caráter universal dos direitos humanos não abrangia demandas específicas de grupos vulneráveis acarretou um processo de especificação de direitos, conforme Norberto Bobbio (2004), o que fomentou a produção de diversos tratados de direitos humanos cujo público-alvo são sujeitos em concreto que fazem parte de grupos vulnerabilizados, criando o sistema especial de proteção onusiano, do qual a CDPD faz parte.

Nesse contexto, é possível inferir que a Convenção sobre os Direitos das Pessoas com Deficiência é considerada como ponto culminante de um processo de afirmação dos direitos humanos desse grupo populacional, uma vez que se trata de uma convenção complexa, que estabelece vários tipos de direitos aos seus destinatários em uma relação de interdependência, 
além de definir a obrigação dos Estados signatários em realizar medidas idôneas para assegurar as garantias às pessoas com deficiência fornecendo suporte para políticas públicas.

Em seguida, analisou-se a teoria crítica dos direitos humanos de Joaquín Herrera Flores (2005), que delineou uma nova perspectiva acerca desses direitos, a partir de um aspecto cultural, ao invés da tese dominante hegemônica do caráter universal dos direitos inerentes ao homem que vigora nos sistemas internacionais. O referido autor entende que os direitos humanos são processos de lutas sociais e culturais que buscam garantir os bens necessários para se viver com dignidade, esta em uma concepção universal.

Herrera Flores (2005) propõe decisões para que os indivíduos possam refletir criticamente suas práticas sociais, em busca da concretização dos direitos humanos que, em síntese, procuram pensar novas formas de intervir no meio, ante a problematizações acerca de demandas diversas da realidade, com o objetivo de construir espaços de diálogo que promovam soluções positivas, em seu sentido ativo, para intervir no meio social. Ao lado disso, o referido autor destaca que tais processos de lutas devem ocorrer promovendo o empoderamento dos sujeitos, para que realizem uma "okupação" (Herrera Flores, 2009) dos espaços de diálogo e construção das práticas sociais que buscam efetivar os direitos humanos.

Por fim, a última parte, retomou o processo histórico de afirmação dos direitos das pessoas com deficiência para destacar a quarta fase que estabelece o paradigma social dos direitos humanos em relação a esses indivíduos, dotando-os de titularidade de garantias expressas em variadas normas, das quais se destacam a CDPD, que originou a promulgação da Lei Brasileira de inclusão e das principais políticas públicas para esse púbico-alvo, notadamente, o Plano Viver sem Limite e o Programa Nacional de Direitos Humanos III.

A despeito disso, cabe uma relevante reflexão acerca de uma fase posterior ao modelo social em relação à deficiência, qual seja a do monitoramento. A CDPD prevê um sistema de monitoramento para realizar o acompanhamento da implementação da referida convenção, valendo-se de relatórios periódicos. Embora tais relatórios sejam importantes para a fiscalização do cumprimento da convecção, são necessárias outras formas de acompanhamento, principalmente, que envolvam a sociedade civil e as representações de pessoas com deficiência, as quais possuem um papel importante para a realização da CDPD.

Desse modo, é possível relacionar a contribuição da teoria crítica de Joaquin Herrera Flores para a concretização da Convenção sobre os Direitos das Pessoas com Deficiência ao fomentar uma fase de constante monitoramento e fomento de processos de luta pelas garantias 
básicas desse grupo populacional e construção de práticas sociais empoderadas de pessoas com deficiência, nos níveis individual e grupal, abrangendo os aspectos político, econômico e cultural, no tocante ao alcance da vida digna.

\section{6- REFERÊNCIAS}

BOBBIO, Norberto, 1909- A era dos direitos / Norberto Bobbio; tradução Carlos Nelson Coutinho; apresentação de Celso Lafer. — Nova ed. — Rio de Janeiro: Elsevier, 2004. - $7^{\mathrm{a}}$ reimpressão.

BRASIL. Decreto $n^{0}$ 6.949, de 25 de agosto de 2009 - Convenção Internacional sobre os Direitos das Pessoas com Deficiência e seu Protocolo Facultativo. Disponível em: http://www.planalto.gov.br/ccivil03/ato2007-2010/2009/decreto/ d6949.htm Acesso em 02 abr. 2020.

BRASIL. Lei $\mathbf{n}^{0}$ 13.146, de 6 de julho de 2015 - Lei Brasileira de Inclusão da Pessoa com Deficiência (Estatuto da Pessoa com Deficiência). Disponível em: http://www.planalto.gov.br/ccivil_03/_ato2015-2018/2015/lei/113146.htm Acesso em 02 abr. 2020.

BRASIL. Observações conclusivas sobre o relatório inicial do Estado Brasileiro. Disponível em: http://www.pessoacomdeficiencia.gov.br/app/relatorio-de-monitoramento-daconvencao Acesso em 13 ago. 2018.

BRASIL. Relatório geral da República Federativa do Brasil sobre o cumprimento das disposições da Convenção sobre os Direitos das Pessoas com Deficiência 2008-2010. Disponível em: $\quad$ http://www.pessoacomdeficiencia.gov.br/app/relatorio-de-monitoramento-daconvencao Acesso em 13 ago. 2018.

BRASIL. Relatório Complementar em relação a observações pontuais do Comitê dos Direitos das Pessoas com Deficiência quanto à implementação da respectiva Convenção pelo Brasil. Disponível em: http://www.pessoacom deficiencia.gov.br/app/relatorio-demonitoramento-da-convencao Acesso em 13 ago. 2018.

BRASIL. SECRETARIA DE DIREITOS HUMANOS. RELATÓRIO DE IMPLEMENTAÇÃO DO PNDH-3. / Grupo de Trabalho de Acompanhamento e Monitoramento do PNDH-3. Conselho Nacional dos Direitos Humanos. Brasília. 2015. Disponível em: http://www.biblioteca.presidencia.gov.br/publicacoesoficiais/catalogo/dilma/sdh_relatorio-de-implementacao-do-programa-nacional-de-direitoshumanos_2015.pdf Acesso em 13 mai. 2019. 
INSTITUTO JOAQUÍN HERRERA FLORES - AMÉRICA LATINA. Biografia de Joaquín Herrera Flores. / IJHF - INSTITUTO JOAQUÍN HERRERA FLORES - AMÉRICA LATINA Disponível em: http://www.joaquinherreraflores.org.br/biografia/ Acesso em 24 mai. de 2020.

GALINDO, G. R. B. Entre manutenção e mudança: Uma análise dos primeiros anos da Convenção das Nações Unidas sobre Pessoas com Deficiência. In: Jane Felipe Beltrão; Jose Claudio Monteiro de Brito Filho; Itziar Gómez; Emilio Pajares; Felipe Paredes; Yanira Zúñiga. (Org.). Direitos Humanos dos Grupos Vulneráveis. Manual. 1ed. Barcelona: Universitat Pompeu Fabra, 2014, v. 1, p. 89-106.

GUIMARÃES, Lytton Leite. Grupos Vulneráveis e Desenvolvimento Humano. In: Trindade, Antonio Augusto Cançado. (Org.). A Incorporação das Normas Internacionais de Proteção dos Direitos Humanos ao Direito Brasileiro. 1a. ed. San José: Instituto Interamericano de Direitos Humanos, 1996, v. 1, p. 371-384.

HERRERA FLORES, Joaquín. A reinvenção dos direitos humanos. / Joaquín Herrera Flores; tradução de: Carlos Roberto Diogo Garcia; Antônio Henrique Graciano Suxberger; Jefferson Aparecido Dias. - Florianópolis: Fundação Boiteux, 2009.

HERRERA FLORES, Joaquín. Los derechos humanos como productos culturales. Crítica del humanismo abstrato. Madrid: Catarata, 2005.

KROHLING, Aloisio; MIYAMOTO, Yumi Maria Helena. A contribuição da teoria crítica do direito internacional dos direitos humanos aos direitos das pessoas com deficiência. In: Revista de Estudos Constitucionais, Hermenêutica e Teoria do Direito (RECHTD). vol. 3 n. 2, julho-dezembro 2011. p. 191-205. Disponível em: http://revistas.unisinos.br/index.php/RECHTD/article/view/1096 Acesso em 03 abr. 2020.

LOPES, Laís Vanessa Carvalho de Figueirêdo. Convenção sobre os direitos das pessoas com deficiência da ONU. In: GUGEL, Maria Aparecida; COSTA FILHO, Waldir Macieira da Costa; RIBEIRO; Lauro Luiz Gomes (org.) Deficiência no Brasil: uma abordagem integral dos direitos das pessoas com deficiência. Florianópolis: Obra Jurídica, 2007. p. 192-235.

PIOVESAN, Flávia. Direitos humanos e o direito constitucional internacional / Flávia Piovesan. - 17. ed. São Paulo: Saraiva, 2018.

PIOVESAN, Flávia; SILVA, Beatriz Pereira; CAMPOLI; Heloisa Borges Pedrosa. A PROTEÇÃO DOS DIREITOS DAS PESSOAS COM DEFICIÊNCIA NO BRASIL. In: Temas de direitos humanos / Flávia Piovesan. - 10. ed. São Paulo: Saraiva, 2017. p. 245-258.

RAMOS, André de Carvalho. Curso de Direitos Humanos. 5. ed. São Paulo: Saraiva, 2018. 
RAMOS, André de Carvalho. Teoria geral dos direitos humanos na ordem internacional / André de Carvalho Ramos 6. ed. São Paulo: Saraiva, 2016.

PORTELA, Paulo Henrique Gonçalves. Direito Internacional Público e Privado: Incluindo Noções de Direitos Humanos e Direito Comunitário. - 10. ed. rev., atual. e ampl. - Salvador: JusPODIVM, 2018. 